\title{
Why do you play? The development of the motives for online gaming questionnaire (MOGQ)
}

\author{
Zsolt Demetrovics • Róbert Urbán • Katalin Nagygyörgy • Judit Farkas • \\ Dalma Zilahy • Barbara Mervó • Antónia Reindl • Csilla Ágoston • Andrea Kertész • \\ Eszter Harmath
}

Published online: 13 April 2011

(C) Psychonomic Society, Inc. 2011

\begin{abstract}
Although the majority of research focuses on the risks and disadvantages of online gaming, the present authors suggest that online games also represent new ways of satisfying basic human needs within the conditions of modern society. The aim of our present study was to reveal and operationalize the components of the motivational basis of online gaming. A total 3,818 persons $(90.6 \%$ males; mean age 20.9 years, $S D=5.81)$ were recruited through websites providing online games. A combined method of exploratory and confirmatory factor analysis was applied. The results confirmed our preliminary model as we identified seven motivational factors (social, escape, competition, coping, skill development, fantasy, and recreation), which were used to develop the 27-item Motives for Online Gaming Questionnaire (MOGQ). The seven dimensions identified seem to cover the full range of possible motives for gaming, and the MOGQ proved to be an adequate measurement tool to assess these motives.
\end{abstract}

Keywords Online gaming · Motives · Questionnaire · Exploratory/confirmatory factor analysis

Z. Demetrovics $(\bowtie) \cdot$ K. Nagygyörgy $\cdot$ J. Farkas $\cdot$ D. Zilahy $\cdot$ B. Mervó • A. Reindl • C. Ágoston · A. Kertész • E. Harmath Institute of Psychology, Institutional Group on Addiction Research, Eötvös Loránd University, PO Box 179, H-1580 Budapest, Hungary

e-mail: demetrovics@t-online.hu

Z. Demetrovics $\cdot$ B. Mervó

National Institute for Drug Prevention,

Budapest, Hungary

R. Urbán

Institute of Psychology, Department of Personality and Health Psychology, Eötvös Loránd University,

Izabella u. 46,

H.1064 Budapest, Hungary
In 2007, more than 217 million users played games online (ComScore, 2007). The majority of research on online gaming has focused on its risks and disadvantages (e.g., $\mathrm{Ng}$ \& Wiemer-Hastings, 2005; Peters \& Malesky, 2008; Whang \& Chu, 2007; Young, 2004). Although many studies have pointed out the possible advantages of gaming as well (e.g., Griffiths 2009; Ng \& Wiemer-Hastings, 2005; Wang, Khoo, Liu, \& Divaharan, 2008), this aspect has received much less attention. Popularity of the games suggests that they satisfy basic needs of people; therefore, they cannot be labeled simply in terms of good or bad. Instead, their characteristics could be examined from a motivational perspective by exploring the needs and motives behind playing them without contemplating their beneficial or harmful nature. Motives are sets of knowledge representing emotional preferences manifested in our thoughts and ideas, and they refer to specific desirable or undesirable aims and categories of aims (McClelland, 1985). These motives can be regarded as energizing and determining factors of our behavior.

The results of studies aimed at describing the motivational background of youth alcohol use also support these considerations (Cooper, Frone, Russell, \& Mudar, 1995; Cox \& Klinger, 1988). These studies pointed out that in the case of alcohol use, motives mediate other important determinants of drinking, such as personality and expectancies (Kuntsche, Knibbe, Engels, \& Gmel, 2007; Urbán, Kökönyei, \& Demetrovics, 2008). Moreover, motives explain up to $50 \%$ of the variance in adolescent alcohol use (Kuntsche, Knibbe, Gmel, \& Engels, 2005). On the basis of these results, we suggest that examination of the motivational background of gaming can be just as important.

Bartle (2003) presented the first motivational approach regarding gaming based on observing Multi-User Dungeon 
(MUD) players. Bartle suggested that motives are associated with four different playing styles. According to his concept, "achievers" are motivated by achieving the aims set up by the game. "Explorers," on the contrary, are more interested in the structure of the virtual world, and the exploration and conquest of unknown scenes and possibilities. "Socializers" are motivated by building relationships and role playing, whereas "killers" use the virtual environment for disturbing and annoying other players. Bartle, however, did not empirically test this model. This was attempted by Yee (2006), who tested a 40-item questionnaire based on Bartle's dimensions on a sample of massively multiplayer online role-playing game players. However, analyzing the data using principal component analysis yielded 10 instead of four different motivational components, and they were finally classified into three comprehensive motivational categories. These categories were achievement (advancement, mechanics, competition), social (socializing, relationship, teamwork), and immersion (discovery, role playing, customization, escapism). The results also suggested that different categories are not exclusive because more than one category can simultaneously characterize the players. However, while taking Bartle's model as the starting point, Yee did not propose the existence of any other dimensions that were not present in the original model. Therefore, it is difficult to estimate to what extent the 40-item inventory covers all possible motivational aspects. In another study, FrostlingHenningsson (2009) examined online first-person-shooter and role-playing game players through combined interviews and observations. According to his results, the social aspects of playing (cooperation and communication) were the main motivation for gaming in addition to escapism (avoiding problems) and seeking the experience of flow. According to Csíkszentmihályi (1990), flow is a state of concentration or complete absorption with the activity. The flow state is characterized by the feeling of engagement, fulfillment, and skill, during which temporal concerns (time, food, ego-self, etc.) are typically ignored. Additional results of the study that were based on self-reports indicated that gamers rated experiences of the virtual world as more exciting than experiences gained from real circumstances. Another stream of research aimed to differentiate between the intrinsic and extrinsic nature of motives. Hsu and $\mathrm{Lu}$ (2007) found that satisfaction of intrinsic motives, such as entertainment, fun, curiosity, exploration, or seeking the experience of flow, increases users' commitment toward the game. Wan and Chiou (2007) obtained similar results applying the Online Gaming Motivation Scale based on knowledge gathered on Multi-User Dungeons and Internet and online gaming motivation. However, psychometric characteristics of the questionnaire have not yet been analyzed.
Overall, the few studies carried out have unambiguously indicated that examining motives can be an important aspect of understanding the nature of online games and gamers. At the same time, the problem is that former studies analyze only one or two types of games and not the entire scale of games, which makes the motivational bases of different games hardly comparable. Therefore, these studies have failed to cover the entire scope of possible motivations or to apply such methods that could have revealed them in a reliable way. Considering the aforementioned facts, the aim of our research was two-fold. First, we aimed to reveal the components of the motivational basis of online games. Second, we aimed to operationalize these dimensions and thus develop a scale to measure the identified dimensions.

\section{Method}

Sample and procedure

The present study analyzed two samples. Motivational items related to online gaming were generated using the first sample consisting of 15 persons (11 males and 4 females) who were recruited by snowball sampling, who play online games on a regular basis (a detailed procedure will be described).

The second sample served as a basis for statistical analysis. When recruiting this sample, we identified all Hungarian websites that facilitate playing online games. Altogether, we identified 18 sites. We contacted all of them, asked for information on the number of visitors, and requested their cooperation in the planned study. All sites answered our question. On the basis of this information, the number of (ever) registered users was estimated to be approximately 30,000 . However, many of these users might be using multiple sites simultaneously. At the same time, it is also likely that many of the formerly registered users are not active anymore. We do not have adequate information to provide information on the overlapping number of active and inactive users. All sites agreed to publish our short call for participation on their home sites or in the form of a newsletter. In the call for participation, we asked the users of the site to visit our website created for this aim, to sign in with a password provided by us, and to complete our questionnaire.

Altogether, 7,520 persons visited our website; however, 3,130 individuals did not answer any questions on the questionnaire. We received altogether 4,390 (58.4\%) questionnaires, although not all of them were totally completed. In addition to answering the general questions regarding online gaming habits, 3,818 respondents completed the entire questionnaire on motives for online gaming. Hence, 
the analysis was carried out on this sample of 3,818 persons.

\section{Measures}

Major sociodemographic characteristics of persons (gender, age, qualification, marital status, school, work) and characteristics regarding their online gaming activities were recorded. Besides these, the survey contained our 56-item questionnaire on motives for online gaming and a few additional questionnaires, which fall outside the scope of the present analysis. Development of the 56-item list of motives was carried out in several steps.

The development of the item list for the motives for online gaming questionnaire First (a), by means of a literature review, we collected all statements that refer to the motivational basis of online gaming, identifying 42 statements altogether. (b) At the same time, 15 persons regularly playing online games were asked to list as many internal reasons and motives for gaming as possible. They were asked to complete the following sentence: "I play online games because..." Overall, 87 motives were collected from the 15 persons. (c) Consecutively, on the basis of the literature, by means of a theoretical reconsideration, these 129 motives were categorized into seven motivational areas: coping-escape, fantasy, skill development, omnipotence (power), recreation, competition, and social motives. Three independent raters (all of them psychologists involved in motivational research) classified these 129 statements into the given categories, and if it was not possible to classify the statement, they could propose a new category as well. At the same time, raters were asked to eliminate those statements from the list that did not clearly refer to internal motives, which led to the exclusion of 38 items. When classifying the remaining 91 items, if no consensus was achieved concerning the classification of an item, the raters had another opportunity for reconciliation. Raters did not suggest any new motivational areas (categories); all items could be assigned unambiguously to the seven given categories. In the next step, the final 91 items were subject to another review, and duplicates were excluded. Therefore, our final list contained 56 items that have become the items of our questionnaire. Table 1 lists all 56 items assigned to the theoretically defined dimensions.

\section{Statistical analysis}

We performed a confirmatory factor analysis (CFA) on the 56 -item scale testing the originally proposed seven-factor measurement model. Given that our first CFA did not provide adequate fit indices, we selected the analytical procedure described by Brown (2006) and used by Brown, White, and Barlow (2005) and Campbell-Sills, Liverant, and Brown (2004). We examined increasingly restrictive solutions of latent structure (i.e., exploratory factor analysis [EFA], EFA with the CFA framework, and finally CFA). Both exploratory and confirmatory factor analyses were performed with MPLUS 6.0. The maximum-likelihood estimation was used in EFA, and robust maximumlikelihood estimation (MLR) was used in the CFA analyses. In the EFA, goodness of fit is assessed by the root-meansquare error of approximation (RMSEA) and its 90\% confidence interval $(90 \% \mathrm{CI})$, and by a $p$ value smaller than .05 for test of the fit. In the CFA, goodness of fit was evaluated using RMSEA and its $90 \%$ confidence interval $(90 \% \mathrm{CI})$, a $p$ value smaller than .05 for test of close fit, standardized root-mean-square residual (SRMR), comparative fit index (CFI), and Tucker-Lewis Fit Index (TLI). As Brown and as Kline (2005) recommended, multiple indices were selected in order to provide different information for evaluating model fit.

To carry out the aforementioned analyses, we randomly selected four nonoverlapping groups from our sample. Sample $1(N=600)$ was used to perform an initial EFA of the original 56 items. Sample $2(N=600)$ was used to conduct a separate EFA to cross-validate the factor structure found in the first analysis. Samples 1 and 2 were merged to test modified pool of items (e.g., solutions that excluded problematic items) and acquire estimates for the final EFA solution. Sample $3(N=600)$ was used to conduct an EFA with the CFA framework in order to establish a more realistic measurement model. The advantage of this step is that it provides an opportunity to test the statistical significance of cross loadings and the potential presence of salient error covariances (Brown, 2006). Samples 1-3 inform the specification of an appropriate CFA solution in Sample $4(N=2,018)$.

\section{Results}

\section{Descriptive statistics}

Of the total sample, $90.6 \%$ of the respondents were males. Mean age was 20.9 years $(S D=5.81)$. Overall, $43.3 \%$ of the sample was 18 years old or younger, and $35.5 \%$ was between 19 and 24 years old. Individuals between 25 and 29 years of age comprised $11.4 \%$ of the sample, whereas respondents older than 29 years constituted less than one-tenth $(9.8 \%)$ of the sample. Nearly two-thirds $(65.1 \%)$ of individuals were single, an additional $21.9 \%$ had a partner who did not live in the same household, and $12.1 \%$ of individuals lived together with a spouse. The rest of the sample, less than $1 \%$, was divorced 


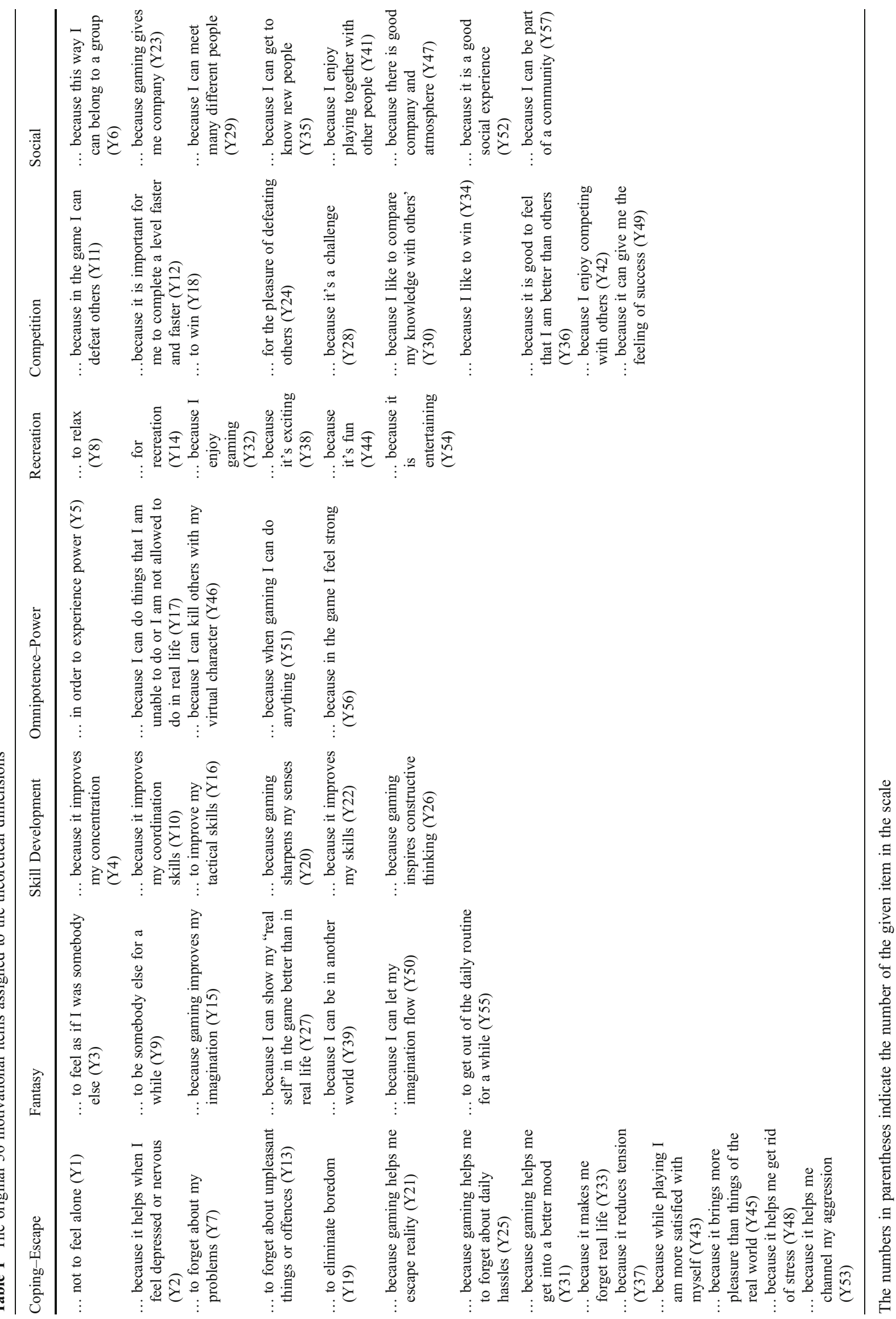


or widowed. Every second respondent attended primary or secondary school, whereas $19.5 \%$ studied at a college or university.

Confirmatory factor analysis with the original items of the motives for online gaming questionnaire

We performed a confirmatory factor analysis with the originally proposed model of the 56-item pool in the total sample $(N=3,818)$. The fit indices indicated inadequate fit to the data $\left(\chi^{2}=45454.7, d f=1,426, p<.0001 ; \mathrm{CFI}=0.627\right.$; $\mathrm{TLI}=0.607$; $\mathrm{RMSEA}=0.089[0.088-0.089]$; $\mathrm{Cfit}=0.001$; SRMR $=0.138$ ). Instead of extensively searching for the sources of misfit in modification indices and regression residuals, we decided to move toward a more explorative analysis, as described in the section Statistical Analysis.

\section{Exploratory factor analyses}

We performed an exploratory factor analysis with maximum-likelihood estimation and promax rotation to evaluate the factor structure of 56 items on Sample $1(N=$ 600). Acceptability of the factor solution was based on the goodness-of-fit index (RMSEA $<0.08$, Cfit $[90 \%$ $\mathrm{CI}]<0.08$ ), the interpretability of the solution, and salient factor loadings $(>0.30)$. We examined six, seven, eight, and nine factor solutions. RMSEA values were 0.062 $[0.060-0.063]$ Cfit $<.0001$ for six-factor solution; 0.057 [0.055 - 0.059] Cfit $<.001$ for seven-factor solution; 0.053 [0.051 - 0.055], Cfit $90 \%=0.009$ for eight-factor solution; and finally $0.050[0.048-0.052]$ Cfit $=0.573$ for nine factors. Therefore, the nine-factor solution was retained $\left(\chi^{2}=3,356.3\right.$, $d f=1,072, p<.0001)$.

We repeated the exploratory factor analysis on Sample 2 $(N=600)$. As in Sample 1, a nine-factor solution also provided the best and most interpretable factor solution $\left(\chi^{2}=2551.5, d f=1,072, p<.0001 ;\right.$ RMSEA $=0.048$ $[0.046-0.050]$, Cfit $=0.919)$. As is presented in Table 2, factor 7 is not interpretable because of the lack of items with factor loadings greater than 0.60 .

In the selection process, we used the following rules: First, we excluded items that had factor loadings less than 0.30 in at least in one of the two analyses. Second, we excluded items with salient cross loadings. If we identified a cross loading only in one of the two parallel EFAs, we used the cutoff 0.50 . In case of more than two cross loadings, we used 0.30 as a cutoff to exclude items from further analyses. The excluded items are crossed out in Table 2. As result of the aforementioned criteria, we retained 44 of the original 56 items. After removing the items, factor 9 included only two items (Items 28 and 41); therefore, we excluded this factor from the later analyses.
In the next step, we again ran an exploratory factor analysis with the remaining 42 items on the combined sample comprising Sample 1 and Sample $2(N=1,200)$. The examination of fit indices [solution $\left(\chi^{2}=2444.8, d f=\right.$ 588, $p<.0001$; RMSEA $=0.051[0.049-0.053]$; Cfit $=$ $0.153]$ and the interpretability of factors supported a sevenfactor solution. Table 3 presents the matrix of factor loadings. Looking at the content of the factors, the original theoretical dimensions (Table 1) have changed at two points. On the one hand, the original coping-escape dimension in fact proved to comprise two separate dimensions that we have labeled Escape and Coping. On the other hand, the omnipotence-power dimension did not appear in the empirical structure. Three items originally listed here $(5,46,56)$ dropped out during the first round of analysis, whereas another two items $(17,51)$ proved to belong to the fantasy factor. Apart from these two modifications, the empirical analysis confirmed the presumed dimensions and item distribution. Correlations between factors ranged from .27 to .58 . The strongest correlation was found between factor 1 (escape) and factor 2 (coping) scales. We could identify two items with salient $(\geq .30)$ cross loadings.

Exploratory factor analysis in the confirmatory factor analysis approach

Sample 3 was used to cross validate the seven-factor solution involving the 42 remaining items. As a transitional step between EFA and CFA, we applied EFA utilizing the CFA approach (E/CFA, Brown, 2006) on Sample 3. In this approach, one anchor item for each factor should be identified from the previous exploratory factor analysis. We used items $3,22,33,34,35,48$, and 54 as anchors for the seven factors. In the first analysis, we did not need to specify any correlations between error terms, which is an important advantage of CFA approach over the usual EFA. The model fit was close to adequate $\left(\chi^{2}=1577.4, d f=588\right.$, $p<.0001 ; \mathrm{CFI}=0.929 ;$ TLI $=0.896 ;$ RMSEA $=0.053$ [0.050 - 0.056]; Cfit $=0.061)$.

After the inspection of modification indices and the evaluation of the content of the items, we freed the error correlations between Item 47 (...because there is good company and atmosphere) and Item 52 (...because it is a good social experience), as well as between Item 15 (... because gaming improves my imagination) and Item 50 (... because I can let my imagination flow). An analysis of the content of items also explained this correlation. The degree of fit improved significantly and became adequate $\left(\chi^{2}=\right.$ $1348.0, d f=586, p<.0001 ; \mathrm{CFI}=0.945$; TLI $=0.920$; RMSEA $=0.047[0.043-0.050] ;$ Cfit $=0.959 ;$ SRMR $=$ 0.023 ). Factor loadings and factor reliabilities are presented in Table 3 . We could identify only four salient $(\geq .30)$ cross loadings. 
Table 2 Exploratory factor analysis of the MOGQ in Sample 1 and Sample $2(N=600$ for both analyses)

\begin{tabular}{|c|c|c|c|c|c|c|c|c|c|c|c|c|c|c|c|c|c|c|}
\hline \multirow[b]{2}{*}{ Y33 } & \multicolumn{2}{|c|}{ Factor 1} & \multicolumn{2}{|c|}{ Factor 2} & \multicolumn{2}{|c|}{ Factor 3} & \multicolumn{2}{|c|}{ Factor 4} & \multicolumn{2}{|c|}{ Factor 5} & \multicolumn{2}{|c|}{ Factor 6} & \multicolumn{2}{|c|}{ Factor 7} & \multicolumn{2}{|c|}{ Factor 8} & \multicolumn{2}{|c|}{ Factor 9} \\
\hline & 0.82 & 0.54 & -0.02 & -0.08 & .07 & & -0.08 & -0.03 & 0.06 & -0.07 & 0.00 & -0.08 & 0.04 & 0.18 & -0.02 & 0.05 & 0.03 & 0.05 \\
\hline Y21 & 0.72 & 0.58 & -0.03 & -0.16 & & & & -0.02 & & -0.05 & -0.04 & -0.01 & -0.06 & 0.04 & -0.04 & 0.07 & & -0.06 \\
\hline & 0.71 & 0.76 & 0.32 & 0.07 & -0.02 & & -0.11 & -0.06 & & 0.01 & -0.03 & -0.07 & -0.25 & -0.01 & -0.08 & -0.02 & 0.03 & 0.03 \\
\hline 46 & 0.64 & 0.25 & -0.10 & -0.02 & 0.15 & 0.60 & & -0.04 & -0.04 & -0.05 & -0.07 & -0.05 & & & -0.17 & -0.16 & 0.02 & 0.02 \\
\hline 44 & 0.60 & 0 . & -0.06 & -0.02 & -0.09 & & & 0.03 & & 0.09 & & -0.08 & & & -0.03 & -0.05 & 0.04 & 0.00 \\
\hline & 0.59 & 0.36 & -0.13 & -0.01 & & & & & & -0.12 & & & & & & 0.14 & & -0.01 \\
\hline & 0.59 & 0.78 & 0.31 & 0.02 & -0.05 & -0.04 & & 0.05 & & 0.11 & & & & & & 0.05 & & -0.11 \\
\hline & 0.50 & 0.77 & & & & & & -0.08 & & 0.09 & & & & & & -0.03 & & -0.04 \\
\hline 56 & 0.46 & & & & & & & -0.09 & & -0.11 & & & & & & -0.07 & & \\
\hline 27 & 0.43 & 0.11 & -0.01 & & & & & 0.07 & & 0.00 & & & & & & & & \\
\hline 49 & -0.04 & 0.16 & 0.87 & 0.73 & -0.04 & -0.04 & & -0.01 & & -0.04 & -0.03 & & & & & -0.08 & & 0.03 \\
\hline 37 & -0.03 & 0.18 & 0.74 & 0.61 & -0.01 & 0.03 & 0.00 & 0.00 & -0.04 & -0.05 & -0.01 & -0.02 & & & & -0.11 & & 0.00 \\
\hline 54 & -0.05 & 0.06 & 0.69 & 0.69 & 0.04 & 0.07 & 0.04 & 0.11 & & 0.04 & -0.07 & -0.06 & & & & 0.04 & 0.01 & 0.00 \\
\hline & 0.16 & 0.45 & 0.60 & & -0.01 & -0.02 & 0.00 & 0.03 & & -0.10 & 0.02 & -0.01 & & & & & & 0 . \\
\hline 31 & 20 & 0.26 & .39 & & 0 & & & -0.01 & & 0.07 & & 0.19 & & & & & & -0.04 \\
\hline & 11 & -0.05 & 0.01 & -0.05 & 0.71 & 0.80 & -0.04 & -0.03 & -0.04 & -0 . & 0.02 & & & & & & & 01 \\
\hline 51 & 0.05 & 0.02 & 0.01 & -0.05 & 0.70 & 0.66 & & -0.03 & & -0.05 & 0.01 & & & & & & & 0.18 \\
\hline 15 & -0.06 & -0.02 & -0.06 & -0.09 & 0.66 & & & & & -0.02 & 0.05 & 0.06 & & & & & & \\
\hline 39 & 0.30 & 0.08 & -0.11 & -0.05 & 0.65 & 0.8 & & -0.07 & & & & & & & & & & \\
\hline 17 & -0.03 & -0.04 & 0.03 & -0.01 & 0.65 & & & & & & & & & & & & & \\
\hline & 0.20 & 0.19 & 0.04 & & & & & & & & & & & & & & & -0.06 \\
\hline 52 & -0.04 & -0.09 & & & & & & & & & & & & & & & & -0.04 \\
\hline & 0.03 & -0.04 & 0.01 & & & & & & & & & & & & & & & \\
\hline Y22 & -0.01 & -0.01 & -0.04 & & & & & & & & & & & & & & & -0.01 \\
\hline 10 & 0.01 & -0.06 & 0.05 & & & & & & & & & -0.05 & & & & & & \\
\hline & 0.01 & -0.08 & 0.01 & & -0.03 & & & & & & & & & & & & & -0.02 \\
\hline 20 & -0.04 & 0.09 & 0.08 & -0.01 & -0.01 & & & & & & -0.04 & & & & -0.02 & & -0.07 & -0.07 \\
\hline 16 & -0.06 & -0.06 & -0.08 & -0.06 & & & & & & & & & & & & & & \\
\hline Y26 & 0.03 & & & & & & & & & & & & & & & & & \\
\hline Y18 & -0.06 & 0.09 & & -0.16 & & & & & & & & & & & & & & \\
\hline Y34 & -0.05 & 0.03 & -0.02 & -0.05 & & & & & & & & & & & & & & \\
\hline Y24 & 0.01 & 0.03 & & & & -0.06 & & & & & & & & & & & & 0.02 \\
\hline Y36 & 0.05 & -0.01 & 0.02 & 0.04 & & 0.02 & & & & & & & & & & & & 0.03 \\
\hline Y11 & -0.01 & -0.05 & & 0.00 & & 0.09 & & & & & & & & & & & & -0.10 \\
\hline & -0.02 & & & & & & & & & & & & & & & & & \\
\hline & 0.04 & 0.07 & & & & & & & & & & & & & & & & \\
\hline & 0.20 & -0.18 & & & & & & & & & & & & & & & & -0.17 \\
\hline & -0.02 & -0.04 & 0.05 & 0.08 & & & & & & & & & & & & & & \\
\hline & -0.02 & -0.01 & -0.04 & 0.01 & & & & & & -0.03 & & & & & & & 0.05 & -0.04 \\
\hline Y29 & 0.08 & 0.01 & -0.05 & 0.03 & 0.01 & 0.10 & -0.02 & & -0.11 & -0.03 & 0.86 & & & & 0.08 & & & 0.07 \\
\hline Y23 & -0.05 & 0.02 & -0.01 & -0.06 & 0.03 & 0.02 & & & 0.06 & -0.04 & 0.70 & 0.80 & -0.06 & 0.00 & 0.05 & & -0.14 & -0.08 \\
\hline Y53 & -0.07 & -0.03 & 0.10 & 0.02 & -0.05 & -0.08 & -0.02 & 0.00 & -0.05 & 0.01 & 0.54 & & 0.09 & 0.06 & -0.26 & -0.23 & -0.08 & -0.04 \\
\hline Y42 & -0.01 & -0.01 & 0.01 & -0.04 & -0.01 & -0.03 & -0.12 & -0.06 & 0.07 & 0.00 & 0.47 & 0.63 & -0.02 & 0.16 & -0.23 & -0.32 & 0.26 & 0.13 \\
\hline Y48 & -0.05 & -0.02 & 0.04 & 0.00 & -0.09 & -0.08 & 0.04 & 0.05 & -0.05 & -0.05 & 0.47 & 0.71 & 0.07 & 0.06 & -0.30 & -0.20 & 0.00 & 0.02 \\
\hline Y6 & 0.19 & 0.10 & -0.10 & -0.07 & 0.01 & 0.05 & 0.21 & 0.17 & 0.12 & 0.04 & 0.22 & 0.46 & -0.10 & 0.01 & 0.14 & 0.04 & 0.03 & 0.06 \\
\hline Y57 & 0.30 & 0.04 & 0.04 & 0.11 & 0.10 & 0.49 & -0.02 & -0.02 & 0.20 & 0.32 & -0.04 & 0.00 & 0.47 & 0.16 & -0.01 & 0.07 & 0.01 & 0.03 \\
\hline Y55 & 0.00 & -0.02 & -0.03 & -0.03 & -0.01 & 0.00 & -0.05 & -0.02 & 0.06 & -0.01 & -0.05 & -0.01 & -0.01 & 0.07 & -0.89 & -0.93 & -0.05 & -0.04 \\
\hline Y32 & 0.10 & -0.04 & -0.08 & -0.02 & -0.03 & 0.02 & 0.02 & -0.08 & 0.04 & 0.01 & -0.07 & 0.05 & -0.02 & -0.03 & -0.79 & -0.74 & 0.10 & 0.05 \\
\hline Y45 & 0.10 & -0.06 & -0.05 & -0.02 & -0.02 & 0.14 & 0.01 & 0.13 & 0.01 & -0.02 & -0.01 & 0.01 & 0.07 & 0.05 & -0.75 & -0.73 & 0.01 & -0.12 \\
\hline
\end{tabular}


Table 2 (continued)

\begin{tabular}{|c|c|c|c|c|c|c|c|c|c|c|c|c|c|c|c|c|c|c|}
\hline \multirow[b]{2}{*}{ Y14 } & \multicolumn{2}{|c|}{ Factor 1} & \multicolumn{2}{|c|}{ Factor 2} & \multicolumn{2}{|c|}{ Factor 3} & \multicolumn{2}{|c|}{ Factor 4} & \multicolumn{2}{|c|}{ Factor 5} & \multicolumn{2}{|c|}{ Factor 6} & \multicolumn{2}{|c|}{ Factor 7} & \multicolumn{2}{|c|}{ Factor 8} & \multicolumn{2}{|c|}{ Factor 9} \\
\hline & -0.04 & 0.02 & 0.02 & 0.05 & 0.00 & -0.03 & 0.03 & 0.01 & 0.00 & -0.07 & -0.01 & 0.00 & -0.08 & -0.14 & -0.67 & -0.59 & 0.06 & 0.02 \\
\hline Y38 & 0.05 & -0.04 & 0.04 & 0.02 & 0.15 & 0.16 & 0.01 & 0.07 & 0.09 & 0.09 & -0.06 & 0.00 & -0.03 & -0.05 & -0.54 & -0.50 & 0.21 & 0.22 \\
\hline Y8 & -0.10 & 0.11 & 0.20 & 0.15 & 0.02 & -0.04 & 0.12 & 0.00 & -0.11 & -0.01 & 0.02 & -0.11 & -0.01 & -0.34 & -0.45 & -0.40 & -0.11 & 0.02 \\
\hline Y41 & -0.06 & -0.05 & 0.00 & 0.02 & 0.13 & 0.13 & 0.16 & 0.05 & 0.12 & 0.22 & 0.02 & 0.05 & 0.03 & -0.02 & -0.06 & -0.10 & 0.60 & 0.58 \\
\hline Y28 & -0.03 & 0.01 & -0.02 & 0.01 & 0.06 & 0.05 & 0.19 & 0.03 & 0.18 & 0.32 & -0.03 & 0.07 & -0.07 & -0.08 & -0.13 & -0.06 & 0.51 & 0.51 \\
\hline Y12 & 0.03 & 0.19 & -0.07 & -0.14 & 0.02 & 0.04 & 0.23 & 0.21 & 0.23 & 0.33 & 0.00 & 0.01 & 0.04 & -0.05 & 0.06 & 0.06 & 0.01 & -0.01 \\
\hline Y19 & -0.01 & 0.25 & 0.06 & 0.09 & 0.03 & -0.08 & 0.04 & -0.02 & 0.19 & 0.22 & 0.04 & 0.13 & -0.04 & -0.06 & -0.27 & -0.25 & -0.14 & -0.24 \\
\hline
\end{tabular}

Exploratory factor analysis was conducted with maximum likelihood estimation, promax rotation. Factor loadings $\geq .30$ are in bold

Confirmatory factor analysis

On the basis of the previous analyses on Samples 1, 2, and 3, a seven-factor solution was tested on Sample $4(N=2,018)$. However, in order to construct a useful, short operationalization of the gaming motives, we performed another item selection in order to limit the number of items per each factor. Since four items securely defined a latent construct, we chose four as the upper limit of the number of items in each factor. In order to secure the content validity of each scale, the item selection was based partly on factor loadings as well as on the content of the items. In line with selection, in addition to analyzing the factor loadings when excluding items, we decided to keep those items that represented the contents of the factors as variable as possible. The measurement model and the selected items are presented in Table 4.

This model provided an adequate fit to the data $\left(\chi^{2}=2263.0\right.$, $d f=303, p<.0001 ; \mathrm{CFI}=0.926$; TLI $=0.914$; RMSEA $=$ 0.057 [0.054 - 0.059]; Cfit < 0.001; SRMR = 0.050). When searching for the partial misfit, we identified large error covariances between Items 29 (...because I can meet many different people) and 35 (...because I can get to know new people) in the social factor, Items 4 (...because it improves my concentration) and 10 (...because it improves my coordination skills) in the skill development factor, Items 21 (...because gaming helps me escape reality) and 33 (...because it makes me forget real life) in the escape factor, and, finally, Items 3 (...to feel as if I was somebody else) and 9 (...to be somebody else for a while) in fantasy factor. Freeing these error covariances increased the degree of model fit $\left(\chi^{2}=1909.0\right.$, $d f=299, p=.107$; CFI $=0.939$; TLI $=0.928$; RMSEA $=$ $0.052[0.049-0.054] ;$ Cfit $=0.107 ;$ SRMR $=0.046$ ). Therefore, the final seven-factor model consists of 27 out of 56 original items. The factor loadings, factor reliabilities, internal consistencies, means, and $S D$ s are presented in Table 4.

Characteristics of the seven-factor model

The final seven-factor model described in the Analyses section largely reflects the original, theoretical model
(Table 1). Items that refer to escaping from reality, especially problems of the real world, characterize the first factor labeled Escape. Other items of the original copingescape dimension loaded on the second factor. These items reflect the role of gaming in channeling and coping with distress and aggression and improving mood; therefore, this factor was named Coping. The third factor named Fantasy refers to the motive of stepping out of one's usual identity, trying new identities in a different fantasy world, and trying things that one cannot do in real life. The fourth factor labeled Skill development contains items that signify that the person plays games in order to improve his or her coordination, concentration, or other skills. The Recreation factor contains three items that reflect recreational, relaxing aspects of online gaming. The four items of the sixth factor represent motives of competing with and defeating others in order to feel a sense of achievement. Thus, this factor is labeled Competition. Finally, the seventh factor contains items that emphasize social aspects of gaming, the pleasure of getting to know people, being with others, and playing together with other persons. This set of items was named the Social factor (See the questionnaire in the Appendix).

Correlations among the seven factors Correlations among the factors ranged from .198 to .604 (Table 5). The lowest correlation was between the factors escape and recreation, but relatively low correlations were also present between escape and skill development and competition dimensions. The competition factor also showed a weak correlation with recreation, whereas recreation correlated slightly with skill development. The strongest correlations were found between escape and coping and fantasy.

Distribution of motives in relation to sociodemographic characteristics

Table 4 shows the mean scores of specific motives. Apparently, the recreation factor had the highest mean $(M=$ 4.12; $S D=0.93)$, followed by the social dimension $(M=$ 
Table 3 Latent structure of MOGQ: Exploratory factor analysis $(N=1,200$, Sample 1 and 2$)$ and exploratory factor analysis conducted within the confirmatory factor analysis framework $(N=600$, Sample 3)

\begin{tabular}{|c|c|c|c|c|c|c|c|c|c|c|c|c|c|c|}
\hline & \multicolumn{2}{|c|}{ Escape } & \multicolumn{2}{|c|}{ Coping } & \multicolumn{2}{|c|}{ Fantasy } & \multicolumn{2}{|c|}{ Skill Development } & \multicolumn{2}{|c|}{ Recreation } & \multicolumn{2}{|c|}{ Competition } & \multicolumn{2}{|l|}{ Social } \\
\hline & EFA & $\mathrm{E} / \mathrm{CFA}$ & EFA & $\mathrm{E} / \mathrm{CFA}$ & EFA & $\mathrm{E} / \mathrm{CFA}$ & EFA & E/CFA & EFA & E/CFA & EFA & $\mathrm{E} / \mathrm{CFA}$ & EFA & $\mathrm{E} / \mathrm{CFA}$ \\
\hline Y33* & 0.82 & 0.81 & -0.12 & 0.00 & 0.12 & 0.00 & -0.01 & 0.00 & -0.01 & 0.00 & 0.00 & 0.00 & -0.02 & 0.00 \\
\hline Y21 & 0.82 & 0.99 & -0.12 & -0.19 & 0.12 & -0.02 & 0.05 & 0.17 & -0.00 & 0.07 & -0.07 & -0.08 & -0.04 & -0.05 \\
\hline Y25 & 0.78 & 0.77 & 0.21 & 0.10 & -0.13 & -0.02 & 0.01 & -0.01 & 0.11 & 0.10 & -0.04 & 0.01 & -0.07 & 0.00 \\
\hline Y13 & 0.63 & 0.79 & 0.23 & 0.16 & -0.11 & -0.10 & 0.08 & 0.06 & -0.04 & 0.01 & -0.01 & -0.07 & 0.01 & 0.01 \\
\hline Y45 & 0.57 & 0.38 & -0.08 & 0.16 & 0.22 & 0.12 & -0.04 & -0.03 & 0.12 & 0.04 & 0.06 & 0.11 & -0.03 & -0.01 \\
\hline Y1 & 0.50 & 0.31 & -0.01 & 0.02 & -0.03 & 0.09 & 0.08 & -0.04 & -0.15 & -0.09 & -0.05 & 0.08 & 0.16 & 0.20 \\
\hline Y55 & 0.48 & 0.29 & 0.13 & 0.19 & 0.34 & 0.41 & -0.12 & 0.04 & 0.08 & 0.08 & -0.03 & -0.02 & 0.03 & -0.03 \\
\hline Y $48^{*}$ & 0.03 & 0.00 & 0.85 & 0.88 & -0.01 & 0.00 & -0.05 & 0.00 & 0.05 & 0.00 & 0.01 & 0.00 & 0.03 & 0.00 \\
\hline Y37 & 0.07 & -0.13 & 0.73 & 0.86 & 0.03 & 0.06 & -0.04 & -0.01 & 0.08 & -0.01 & -0.01 & 0.00 & -0.04 & -0.05 \\
\hline Y53 & 0.07 & -0.01 & 0.65 & 0.65 & 0.07 & 0.19 & 0.03 & 0.10 & -0.11 & -0.18 & 0.14 & 0.18 & -0.04 & -0.05 \\
\hline Y2 & 0.28 & 0.26 & 0.56 & 0.50 & -0.08 & -0.04 & 0.06 & 0.03 & -0.10 & -0.05 & -0.10 & -0.04 & 0.04 & -0.04 \\
\hline Y31 & 0.23 & 0.06 & 0.34 & 0.48 & 0.05 & 0.11 & -0.02 & -0.06 & 0.12 & 0.09 & 0.09 & 0.20 & 0.18 & 0.12 \\
\hline Y8 & -0.07 & -0.18 & 0.26 & 0.39 & 0.07 & 0.00 & 0.10 & 0.04 & 0.41 & 0.36 & -0.18 & -0.10 & -0.13 & -0.05 \\
\hline Y3* & 0.08 & 0.00 & -0.03 & 0.00 & 0.76 & 0.74 & -0.02 & 0.00 & -0.12 & 0.00 & -0.09 & 0.00 & 0.05 & 0.00 \\
\hline Y39 & 0.26 & -0.06 & -0.07 & 0.14 & 0.71 & 0.75 & -0.08 & -0.02 & 0.06 & 0.02 & -0.03 & 0.12 & 0.03 & 0.05 \\
\hline Y50 & -0.03 & -0.28 & 0.05 & 0.20 & 0.68 & 0.67 & 0.07 & 0.11 & 0.12 & 0.10 & -0.08 & 0.09 & 0.12 & 0.07 \\
\hline Y17 & 0.11 & -0.11 & 0.00 & 0.09 & 0.66 & 0.62 & 0.01 & 0.14 & 0.02 & -0.10 & 0.12 & 0.28 & -0.07 & 0.03 \\
\hline Y15 & -0.10 & -0.20 & -0.02 & 0.08 & 0.63 & 0.50 & 0.18 & 0.27 & 0.22 & 0.22 & -0.12 & 0.03 & 0.01 & 0.02 \\
\hline Y9 & 0.21 & 0.05 & 0.05 & 0.10 & 0.56 & 0.55 & 0.01 & 0.16 & -0.03 & 0.03 & -0.06 & -0.02 & -0.02 & -0.01 \\
\hline Y51 & 0.11 & -0.12 & 0.11 & 0.26 & 0.55 & 0.67 & -0.03 & 0.02 & 0.08 & -0.13 & 0.27 & 0.33 & -0.04 & 0.00 \\
\hline Y22* & 0.05 & 0.00 & -0.06 & 0.00 & -0.09 & 0.00 & 0.90 & 0.84 & 0.02 & 0.00 & 0.07 & 0.00 & -0.01 & 0.00 \\
\hline Y10 & 0.00 & -0.09 & 0.02 & 0.13 & -0.02 & 0.03 & 0.85 & 0.91 & 0.06 & -0.07 & -0.02 & -0.16 & -0.02 & -0.07 \\
\hline Y4 & -0.10 & -0.15 & 0.07 & 0.14 & 0.11 & 0.12 & 0.79 & 0.85 & -0.13 & -0.07 & -0.04 & -0.11 & 0.01 & -0.07 \\
\hline Y20 & 0.07 & -0.09 & -0.02 & 0.15 & -0.01 & 0.08 & 0.78 & 0.73 & -0.02 & -0.01 & 0.08 & 0.15 & -0.04 & -0.08 \\
\hline Y16 & -0.05 & -0.26 & -0.08 & 0.06 & 0.09 & 0.20 & 0.72 & 0.70 & 0.07 & 0.10 & 0.05 & 0.07 & 0.08 & 0.00 \\
\hline Y26 & 0.09 & -0.13 & 0.00 & 0.13 & 0.01 & 0.15 & 0.62 & 0.59 & 0.11 & 0.08 & 0.00 & 0.05 & 0.05 & 0.03 \\
\hline Y54* & 0.05 & 0.00 & -0.05 & 0.00 & 0.00 & 0.00 & -0.06 & 0.00 & 0.88 & 0.77 & 0.04 & 0.00 & -0.02 & 0.00 \\
\hline Y32 & 0.05 & 0.07 & -0.08 & -0.12 & -0.01 & -0.07 & -0.07 & -0.10 & 0.81 & 0.79 & 0.05 & 0.09 & 0.01 & 0.05 \\
\hline Y14 & 0.02 & -0.04 & 0.06 & 0.11 & -0.02 & 0.01 & 0.04 & 0.03 & 0.65 & 0.60 & -0.11 & -0.07 & -0.06 & -0.09 \\
\hline Y38 & -0.03 & -0.18 & 0.03 & 0.15 & 0.18 & 0.22 & 0.08 & 0.05 & 0.54 & 0.51 & 0.17 & 0.21 & 0.02 & 0.03 \\
\hline Y34* & -0.04 & 0.00 & 0.00 & 0.00 & -0.05 & 0.00 & 0.00 & 0.00 & 0.06 & 0.00 & 0.91 & 0.90 & -0.06 & 0.00 \\
\hline Y24 & 0.01 & 0.14 & 0.02 & -0.08 & -0.04 & -0.02 & 0.02 & 0.08 & 0.00 & 0.02 & 0.89 & 0.79 & -0.07 & -0.04 \\
\hline Y36 & 0.02 & 0.15 & 0.02 & -0.06 & -0.02 & -0.02 & -0.05 & 0.02 & -0.05 & 0.03 & 0.88 & 0.78 & -0.01 & 0.01 \\
\hline Y18 & 0.02 & 0.05 & -0.07 & -0.08 & -0.03 & 0.03 & 0.08 & 0.11 & 0.03 & 0.01 & 0.85 & 0.81 & -0.07 & -0.12 \\
\hline Y11 & -0.03 & 0.05 & 0.00 & -0.11 & 0.15 & 0.18 & -0.03 & 0.16 & -0.13 & -0.05 & 0.77 & 0.72 & -0.05 & -0.10 \\
\hline Y42 & 0.00 & 0.02 & -0.01 & -0.12 & -0.10 & 0.01 & 0.06 & 0.09 & 0.12 & 0.12 & 0.64 & 0.67 & 0.14 & 0.13 \\
\hline Y49 & 0.04 & 0.04 & 0.19 & 0.27 & 0.10 & 0.13 & 0.02 & 0.10 & 0.13 & 0.11 & 0.46 & 0.39 & 0.10 & 0.05 \\
\hline Y $35^{*}$ & -0.01 & 0.00 & 0.01 & 0.00 & 0.03 & 0.00 & -0.01 & 0.00 & -0.11 & 0.00 & -0.03 & 0.00 & 0.97 & 0.93 \\
\hline Y29 & -0.05 & 0.01 & 0.02 & -0.04 & 0.09 & 0.01 & 0.02 & 0.04 & -0.08 & 0.03 & -0.06 & -0.02 & 0.90 & 0.91 \\
\hline Y23 & 0.03 & 0.15 & -0.03 & -0.08 & 0.02 & -0.14 & 0.12 & 0.18 & -0.04 & 0.03 & -0.03 & -0.04 & 0.75 & 0.73 \\
\hline Y52 & 0.00 & 0.04 & 0.03 & -0.02 & -0.01 & -0.08 & -0.04 & 0.01 & 0.23 & 0.21 & 0.02 & -0.02 & 0.68 & 0.60 \\
\hline Y47 & 0.02 & 0.06 & -0.03 & 0.02 & -0.07 & -0.14 & 0.01 & 0.01 & 0.25 & 0.30 & -0.01 & -0.05 & 0.66 & 0.51 \\
\hline Det. & 0.96 & 0.96 & 0.94 & 0.95 & 0.95 & 0.94 & 0.96 & 0.96 & 0.94 & 0.92 & 0.97 & 0.97 & 0.97 & 0.97 \\
\hline
\end{tabular}

Factor loadings $\geq 0.30$ are bold. EFA exploratory factor analysis (maximum likelihood extraction with promax rotation), E/CFA exploratory factor analysis within the confirmatory factor analysis framework (robust maximum likelihood), Det. Factor determinacy

* Items were used as anchor indicators in the E/CFA analysis 
Table 4 Latent structure of MOGQ: Confirmatory factor analysis using Sample $4(N=2,018)$

\begin{tabular}{|c|c|c|c|c|c|c|c|}
\hline & Escape & Coping & Fantasy & Skill Development & Recreation & Competition & Social \\
\hline Y33 & 0.78 & & & & & & \\
\hline Y21 & 0.72 & & & & & & \\
\hline Y25 & 0.85 & & & & & & \\
\hline Y13 & 0.74 & & & & & & \\
\hline Y48 & & 0.82 & & & & & \\
\hline Y37 & & 0.77 & & & & & \\
\hline Y53 & & 0.70 & & & & & \\
\hline Y31 & & 0.72 & & & & & \\
\hline Y3 & & & 0.66 & & & & \\
\hline Y39 & & & 0.83 & & & & \\
\hline Y17 & & & 0.66 & & & & \\
\hline Y9 & & & 0.70 & & & & \\
\hline Y22 & & & & 0.87 & & & \\
\hline Y10 & & & & 0.80 & & & \\
\hline Y4 & & & & 0.73 & & & \\
\hline $\mathrm{Y} 20$ & & & & 0.84 & & & \\
\hline Y54 & & & & & 0.84 & & \\
\hline Y32 & & & & & 0.80 & & \\
\hline Y14 & & & & & 0.63 & & \\
\hline Y34 & & & & & & 0.86 & \\
\hline $\mathrm{Y} 24$ & & & & & & 0.84 & \\
\hline Y36 & & & & & & 0.87 & \\
\hline Y42 & & & & & & 0.74 & \\
\hline Y35 & & & & & & & 0.86 \\
\hline Y29 & & & & & & & 0.85 \\
\hline Y23 & & & & & & & 0.85 \\
\hline Y52 & & & & & & & 0.75 \\
\hline Det. & 0.94 & 0.94 & 0.92 & 0.94 & 0.92 & 0.95 & 0.94 \\
\hline$\alpha$ & 0.87 & 0.84 & 0.82 & 0.89 & 0.79 & 0.90 & 0.90 \\
\hline Mean & 1.91 & 2.49 & 2.33 & 2.25 & 4.12 & 2.42 & 3.03 \\
\hline SD & 1.00 & 1.08 & 1.13 & 1.14 & 0.93 & 1.19 & 1.21 \\
\hline
\end{tabular}

Empty cells represented zero factor loadings in CFA

3.03; $S D=1.21$ ), and then by coping, competition, fantasy, skill development, and, finally, escape dimensions. Men scored higher on the competition factor than women; however, women scored higher on the remaining five factors.
Significant effects of age were also shown. Younger persons had higher mean scores than did older persons on all dimensions except for recreation, on which older persons scored higher (Table 6).
Table 5 Correlations between factors of the MOGQ $(N=3818)$

All correlations are significant at $p<.001$

\begin{tabular}{|c|c|c|c|c|c|c|}
\hline & Coping & Fantasy & Skill development & Recreation & Competition & Social \\
\hline Escape & .602 & .604 & .250 & .198 & .290 & .303 \\
\hline Coping & & .516 & .412 & .426 & .403 & .445 \\
\hline Fantasy & & & .320 & .310 & .310 & .362 \\
\hline Skill Development & & & & .249 & .386 & .458 \\
\hline Recreation & & & & & .257 & .383 \\
\hline Competition & & & & & & .339 \\
\hline
\end{tabular}


Table 6 Mean scores and standard deviations (in parentheses) of factors of the MOGQ related to sociodemographic dimensions $(N=3,818)$

\begin{tabular}{llllllll}
\hline & $\begin{array}{l}\text { Male } \\
(\mathrm{N}=3461)\end{array}$ & $\begin{array}{l}\text { Female } \\
(\mathrm{N}=357)\end{array}$ & $t$ test & $\begin{array}{l}14-17 \text { years } \\
(N=1,239)\end{array}$ & $\begin{array}{l}18-21 \text { years } \\
(N=1,265)\end{array}$ & $\begin{array}{l}22-54 \text { years } \\
(N=1,314)\end{array}$ \\
\hline Escape & $1.86(0.97)$ & $2.29(1.16)$ & $6.746^{* * *}$ & $1.99(1.07)$ & $1.91(0.98)$ & $1.82(0.93)$ & $9.719^{* * *}$ \\
Coping & $2.48(1.08)$ & $2.61(1.01)$ & $2.124^{*}$ & $2.62(1.16)$ & $2.52(1.07)$ & $2.36(0.98)$ & $19.595^{* * *}$ \\
Fantasy & $2.28(1.11)$ & $2.78(1.24)$ & $7.244^{* * *}$ & $2.47(1.16)$ & $2.32(1.14)$ & $2.20(1.08)$ & $17.788^{* * *}$ \\
Skill Development & $2.26(1.16)$ & $2.18(1.02)$ & 1.277 & $2.34(1.17)$ & $2.29(1.14)$ & $2.12(1.11)$ & $13.867^{* * *}$ \\
Recreation & $4.10(0.93)$ & $4.30(0.82)$ & $4.400^{* * *}$ & $4.03(1.00)$ & $4.12(0.91)$ & $4.21(0.86)$ & $11.386^{* * *}$ \\
Competition & $2.47(1.19)$ & $1.87(0.98)$ & $10.900^{* * *}$ & $2.60(1.24)$ & $2.43(1.19)$ & $2.23(1.09)$ & $31.527^{* * *}$ \\
Social & $3.00(1.21)$ & $3.35(1.18)$ & $5.357^{* * *}$ & $3.18(1.23)$ & $3.02(1.19)$ & $2.89(1.20)$ & $17.327^{* * *}$ \\
\hline
\end{tabular}

$* p<.05 ; * * p<.01 ; * * * p<.001$

\section{Discussion}

The aim of our present study was to gain deeper knowledge of and to operationalize the motivational basis of online games. Our combined exploratory and confirmatory analyses principally confirmed our preliminary, theoretically developed model created along the content analysis of motivational items. The theoretical model had to be modified at two points: The coping-escape dimension turned out to comprise two separate, however highly correlated, factors, whereas the dimension of omnipotence-power did not appear in the model in the form we had formerly supposed. The fantasy and competition dimensions represented their content.

An important result of our analysis is that due to generating the original items on an extensive basis and applying diverse sources (scientific literature and online gamers), we could reveal, describe, and operationalize the supposedly comprehensive motivational scale of online gaming. Furthermore, in contrast with former studies (Bartle, 2003; Frostling-Henningsson, 2009; Yee, 2006), the identified seven dimensions are applicable to all types of online games, since we did not limit our sample to any particular game types. Previously identified factors appeared among the seven dimensions identified in this study, and new factors that were not present in former studies also emerged. Even Bartle suggested, and Yee, together with Frostling-Henningson, confirmed the presence of a social factor, which is, according to our results, the second most important motivational dimension. At the same time, it is interesting that the most determinant factor in light of our results, recreation $(M=4.12)$, has not appeared in previous studies. It is likely that former studies that determined the starting dimensions (items) by means of nonempirical methods simply forgot about this dimension, which has no specific content but expresses the basic need for recreation and fun. Although the dimension of escaping reality and problems (escapism) appears in earlier studies, the coping factor identified in our present work, which is clearly differentiated from the former escapism factor, is missing. Although escapism emphasizes leaving reality, the latter emphasizes that gaming helps coping with real problems (stress, aggression, anxiety) and managing unpleasant moods and unwanted impulses. It is important to underline that although escapism is present as a central element in diverse studies, its role in the gaming population is not prominent; the present sample had the lowest mean score (1.91) on this dimension. It is plausible, however, that this motivation is more dominant for problematic gaming, although verification of this statement requires further research. The competition factor can be found in the model of Yee as part of the achievement dimension; nevertheless, former studies did not identify the need for improving various skills as a motivational factor. At last, the fantasy dimension is part of Yee's role-playing factor.

In light of the aforementioned facts, it is important to see that although negative outcomes of online gaming are frequently mentioned, gaming has actually a diverse motivational background and satisfies various real needs. Online games and other applications are usually criticized for binding the users to a PC and virtual reality and therefore potentially distracting them from the real world, real interpersonal relationships, interactions, and activities. However, besides the actual risks of gaming, we have to consider that these applications satisfy basic and concrete human needs in the conditions of our modern society.

Altogether, the most important result of the present study is that, on the basis of the explored motivational background of online games, a research method has been developed that can serve as a reliable basis for future research. Additional studies need to describe and compare different types of games along with their motivational basis as well as to analyze the relations between the motivational background and problematic gaming behavior. Addressing the latter issue might help to identify the dimensions 
predictive of problematic online gaming and the possible risk of addiction. Considering the results of drinking motives research (Cooper et al., 1995; Kuntsche et al., 2005), the authors suppose that mainly the dominance of the coping and escape dimensions indicate problematic gaming; however, future studies would need to test this hypothesis. Another objective of future research in this field is to define the relationship between specific motivational dimensions and different personality traits or characteristics.

The present study was limited to the examination of online games: Therefore, the exploration of other online activities (e.g., tweeting or using other community sites) and examining motivational background of offline games are also tasks for the future. In this aspect, to reveal and to describe specific and general motives for different applications can also be an interesting issue.
Author Note The present work was supported by the Hungarian Ministry of Social Affairs and Labor Grant KAB-KT-09-0007 and the Hungarian Scientific Research Fund Grant 83884. Zsolt Demetrovics acknowledges financial support of the János Bolyai Research Fellowship awarded by the Hungarian Academy of Science.

\section{Appendix. Motives for online gaming questionnaire (MOGQ)}

People play online games for different reasons. Some reasons are listed below.

Please indicate how often you play online games for the reasons listed below by circling the appropriate response almost never/never (1), some of time (2), half of the time (3), most of the time (4), almost always/always (5). There is no right or wrong answer! We are only interested in your motives for gaming.

\begin{tabular}{|c|c|c|c|c|c|c|c|}
\hline & \multicolumn{2}{|l|}{ I play online games... } & $\begin{array}{l}\text { almost never / } \\
\text { never }\end{array}$ & $\begin{array}{l}\text { some of the } \\
\text { time }\end{array}$ & $\begin{array}{l}\text { half of the } \\
\text { time }\end{array}$ & $\begin{array}{l}\text { most of the } \\
\text { time }\end{array}$ & $\begin{array}{l}\text { almost always / } \\
\text { always }\end{array}$ \\
\hline 1. & \multicolumn{2}{|c|}{... because I can get to know new people } & 1 & 2 & 3 & 4 & 5 \\
\hline 2. & \multicolumn{2}{|c|}{$\ldots$ because gaming helps me to forget about daily hassles } & 1 & 2 & 3 & 4 & 5 \\
\hline 3. & \multicolumn{2}{|c|}{... because I enjoy competing with others } & 1 & 2 & 3 & 4 & 5 \\
\hline 4. & \multicolumn{2}{|c|}{... because gaming helps me get into a better mood } & 1 & 2 & 3 & 4 & 5 \\
\hline 5. & \multicolumn{2}{|c|}{$\ldots$ because gaming sharpens my senses } & 1 & 2 & 3 & 4 & 5 \\
\hline 6. & \multicolumn{2}{|c|}{$\begin{array}{l}\text {.. because I can do things that I am unable to do or I am not } \\
\text { allowed to do in real life }\end{array}$} & 1 & 2 & 3 & 4 & 5 \\
\hline 7. & \multicolumn{2}{|c|}{$\ldots$ for recreation } & 1 & 2 & 3 & 4 & 5 \\
\hline 8. & \multicolumn{2}{|c|}{... because I can meet many different people } & 1 & 2 & 3 & 4 & 5 \\
\hline 9. & \multicolumn{2}{|c|}{... because it makes me forget real life } & 1 & 2 & 3 & 4 & 5 \\
\hline 10 & \multicolumn{2}{|c|}{$\ldots$ because I like to win } & 1 & 2 & 3 & 4 & 5 \\
\hline 11. & \multicolumn{2}{|c|}{$\ldots$ because it helps me get rid of stress } & 1 & 2 & 3 & 4 & 5 \\
\hline 12. & \multicolumn{2}{|c|}{$\ldots$ because it improves my skills } & 1 & 2 & 3 & 4 & 5 \\
\hline 13. & \multicolumn{2}{|c|}{$\ldots$ to feel as if I was somebody else } & 1 & 2 & 3 & 4 & 5 \\
\hline 14. & \multicolumn{2}{|c|}{$\ldots$ because it is entertaining } & 1 & 2 & 3 & 4 & 5 \\
\hline 15. & \multicolumn{2}{|c|}{$\ldots$ because it is a good social experience } & 1 & 2 & 3 & 4 & 5 \\
\hline 16. & \multicolumn{2}{|c|}{... because gaming helps me escape reality } & 1 & 2 & 3 & 4 & 5 \\
\hline 17. & \multicolumn{2}{|c|}{... because it is good to feel that I am better than others } & 1 & 2 & 3 & 4 & 5 \\
\hline 18. & \multicolumn{2}{|c|}{$\ldots$ because it helps me channel my aggression } & 1 & 2 & 3 & 4 & 5 \\
\hline 19. & \multicolumn{2}{|c|}{$\ldots$ because it improves my concentration } & 1 & 2 & 3 & 4 & 5 \\
\hline 20 . & \multicolumn{2}{|c|}{... to be somebody else for a while } & 1 & 2 & 3 & 4 & 5 \\
\hline 21. & \multicolumn{2}{|l|}{... because I enjoy gaming } & 1 & 2 & 3 & 4 & 5 \\
\hline 22 . & \multicolumn{2}{|c|}{$\ldots$ because gaming gives me company } & 1 & 2 & 3 & 4 & 5 \\
\hline 23. & \multicolumn{2}{|c|}{$\ldots$ to forget about unpleasant things or offences } & 1 & 2 & 3 & 4 & 5 \\
\hline 24. & \multicolumn{2}{|c|}{$\ldots$ for the pleasure of defeating others } & 1 & 2 & 3 & 4 & 5 \\
\hline 25 . & \multicolumn{2}{|c|}{$\ldots$ because it reduces tension } & 1 & 2 & 3 & 4 & 5 \\
\hline 26. & \multicolumn{2}{|c|}{... because it improves my coordination skills } & 1 & 2 & 3 & 4 & 5 \\
\hline 27. & \multicolumn{2}{|c|}{$\ldots$ because I can be in another world } & 1 & 2 & 3 & 4 & 5 \\
\hline & Escape & Competition & & Skill Developm & & Fantasy & Recreation \\
\hline & $2,9,16,23$ & $3,10,17,24$ & 18,25 & $5,12,19,26$ & & $6,13,20,27$ & $7,14,21$ \\
\hline
\end{tabular}




\section{References}

Bartle, R. (2003). Designing virtual worlds. Indianapolis: New Riders. Brown, T. A. (2006). Confirmatory factor analysis for applied research. New York: Guilford.

Brown, T. A., White, K. S., \& Barlow, D. H. (2005). A psychometric reanalysis of the Albany Panic and Phobia Questionnaire. Behaviour Research and Therapy, 43, 337-355.

Campbell-Sills, L., Liverant, G. I., \& Brown, T. A. (2004). Psychometric evaluation of the behavioral inhibition/behavioral activation scales in a large sample of outpatients with anxiety and mood disorders. Psychological Assessment, 16, 244-254.

ComScore (2007). Worldwide online gaming community reaches 217 million people. Retrieved from http://www.comscore.com/ Press_Events/Press_Releases/2007/07/Worldwide_Online_ Gaming_Grows

Cooper, M., Frone, M., Russell, M., \& Mudar, P. (1995). Drinking to regulate positive and negative emotions: A motivational model of alcohol use. Journal of Personality and Social Psychology, 69, 990-1005.

Cox, W., \& Klinger, E. (1988). A motivational model of alcohol use. Journal of Abnormal Psychology, 97, 168-180.

Csíkszentmihályi, M. (1990). Flow: The psychology of optimal experience. New York: Harper and Row.

Frostling-Henningsson, M. (2009). First-person shooter games as a way of connecting to people: "Brothers in blood." Cyberpsychology and Behavior, 12, 557-562.

Griffiths, M. D. (2009). The role of context in online gaming excess and addiction: Some case study evidence. International Journal of Mental Health and Addiction, 8, 119-125.

Hsu, C., \& Lu, H. (2007). Consumer behavior in online game communities: A motivational factor perspective. Computers in Human Behavior, XX, 1642-1659.

Kline, R. B. (2005). Principles and practice of structural equation modeling (2nd ed.). New York: Guilford.
Kuntsche, E., Knibbe, R., Gmel, G., \& Engels, R. (2005). Why do young people drink? A review of drinking motives. Clinical Psychology Review, 25, 841-861.

Kuntsche, E., Knibbe, R., Engels, R., \& Gmel, G. (2007). Drinking motives as mediators of the link between alcohol expectancies and alcohol use among adolescents. Journal of Studies on Alcohol and Drugs, 68, 76-85.

McClelland, D. (1985). How motives, skills, and values determine what people do. American Psychologist, XX, 812-825.

Ng, B., \& Wiemer-Hastings, P. (2005). Addiction to the internet and online gaming. Cyberpsychology and Behavior, 8, 110 113.

Peters, C., \& Malesky, L. (2008). Problematic usage among highly-engaged players of massively multiplayer online role playing games. Cyberpsychology and Behavior, 11, 481484.

Urbán, R., Kökönyei, G., \& Demetrovics, Z. (2008). Alcohol outcome expectancies and drinking motives mediate the association between sensation seeking and alcohol use among adolescents. Addictive Behaviors, 33, 1344-1352.

Wan, C., \& Chiou, W. (2007). The motivations of adolescents who are addicted to online games: A cognitive perspective. Adolescence, 42, 179-197.

Wang, C., Khoo, A., Liu, W., \& Divaharan, S. (2008). Passion and intrinsic motivation in digital gaming. Cyberpsychology and Behavior, 11, 39-45.

Whang, C., \& Chu, Y. (2007). Harmonius and obsessive passion in playing online games. Social Behaviour and Personality, 35, 997-1006.

Yee, N. (2006). The demographics, motivations, and derived experiences of users of massively multi-user online graphical environments. Presence-Teleoperators and Virtual Environments, XX, 309-329.

Young, K. (2004). Internet addiction-A new clinical phenomenon and its consequences. American Behavioral Scientist, XX, 402 415. 